\title{
Editorial: Advanced Learning Technologies, Performance Technologies, Open Contents, and Standards - Some Papers from the Best Papers of the Conference ICCE C3 2009
}

\section{Fanny Klett*}

Business Area Data Representation and Interfaces

Fraunhofer Institute Digital Media Technology

98693 Ilmenau, Germany

E-mail: fanny.klett@idmt.fraunhofer.de

\section{Kiyoshi Nakabayashi*}

Faculty of Information and Computer Science

Chiba Institute of Technology

2-17-1 Tsudanuma, Narashino-Shi, Chiba 275-0016, Japan

E-mail: knaka@net.it-chiba.ac.jp

\section{Stephen J.H. Yang*}

Department of Computer Science and Information Engineering,

National Central University, No.300, Jhongda Rd., Jhongli City,

Taoyuan County 32001, Taiwan

E-mail: jhyang@csie.ncu.edu.tw

*Corresponding author

\begin{abstract}
This special issue deals with several cutting edge research outcomes from recent advancement of learning technologies. Advanced learning technologies are the composition of various related technologies and concepts such as i) internet technologies and mobile technologies, ii) human and organizational performance/knowledge management, and iii) underlying trends toward open technology, open content and open education. This editorial note describes the overview of these topics related to the advanced learning technologies to provide the common framework for the accepted papers in this special issue.
\end{abstract}

Keywords: learning technology, Web2.0, mobile technology, performance management, open education, technology standardization

Biographical notes: Fanny Klett (Ph.D.) leads the Data Representation and Interfaces Business Area at the Fraunhofer Institute for Digital Media Technology. She assumed the Directorship of the German Workforce ADL Partnership Lab in 2009. Dr. Klett's interests focus on synergies between distributed learning and training, and applied research and development in the fields of information and content management, digital libraries as well as competency and performance management. She serves as a Principal Investigator and Coordinator on projects in these areas that are funded by various programs of the European Commission and the German government. 
Dr. Klett actively works on the IEEE Learning Technology Standards Committee and in ISO JTC 1/SC 36, Information Technology for Learning, Education and Training. She has published over 60 technical papers and book chapters, and was awarded patents in the area of educational technology. Dr. Klett is associate editor of the IEEE Education Society and ASEE Electrical and Computer Engineering Division joint publication "The Interface", serves on the review boards of the IEEE Transactions on Education and the IEEE Educational Technology and Society Journal as well as being a peer-reviewer for the European Commission R\&D Program. Dr. Klett is IEEE Fellow and chairs committees on the IEEE Educational Activities Board and the IEEE Computer Society Chapter Activities Board as well as the German Chapter of the IEEE Education Society. She is also Member of the Council and the Academic Board of the European Association for Education in Electrical and Information Engineering.

Dr. Kiyoshi Nakabayashi is currently a Professor at the Chiba Institute of Technology in Japan. After receiving his M.Sc. from the Tokyo Institute of Technology in 1982, he entered the Electrical Communications Laboratory of Nippon Telegraph and Telephone Corp. where he has been engaged in research and development on parallel processing, character recognition systems, and network-based learning-support systems. He received his Ph.D in Human Science from Waseda University in 2006. His research interests include the design of learning support systems, especially their system architectures and the related standardization of e-learning technology.

Dr. Stephen J.H. Yang is a Distinguished Professor of Computer Science \& Information Engineering, and the Associate Dean of Academic Affairs at the National Central University, Taiwan. Dr. Yang received his Ph.D. degree in Electrical Engineering \& Computer Science from the University of Illinois at Chicago in 1995. Dr. Yang has published over 180 papers, his research interests include knowledge management, Second Life, mobile learning, Web 2.0, semantic Web, social networks, context aware \& ubiquitous learning.

\section{Introduction}

There is a long history of information and communication technology (ICT) application in education. The wide spread of the Internet, however, generates new trends in the educational application of ICT, similarly to the industrial fields. These trends include:

- Dissemination of high performance and low-cost terminals and network connections enhancing personalized services by exploiting massively accumulated personal profiles.

- Creation of numerous network-based open communities, free from the barrier of time and distance, sharing and generating of information and knowledge.

- Rise of open technologies, open contents and open standards accelerating the trends toward open education.

Advanced learning technologies reflect the composition of these new trends in addition to the traditional research areas including but not limited to learner adaptive systems, content design, testing theory, instructional design, learning theory, knowledge management, and so on. This editorial note aims to provide an overview of the joint 
trends in these areas related to advanced learning technologies as a common framework for the accepted papers in this special issue.

\section{Personalized Systems, Mobile Technologies and Web2.0 Technologies}

Web 2.0 refers to an expected second generation of the Web that allows people to create, publish, exchange, share, and cooperate on information in a new way of communication and collaboration. Web 2.0 makes the Internet not only for browsing, but also for creating and sharing content and information. Applying Web 2.0 to e-learning is to enhance learner-centric communication and collaboration among participants in Web-based learning. In Web 2.0, learners can read and write to the Web, in which learners become the consumers and producers of learning resources. Web 2.0 also shapes new pedagogy for learning and instruction. By applying Web 2.0, educators can easily achieve the ideal of practicing constructivism which emphasizes on peer negotiation, knowledge construction and co-construction.

The emergence of Web 2.0 not only accelerates the development of diverse communities but also promotes socialization of the Internet. The success of Web 2.0 heavily relies on interactive communication and collaboration among people over the Internet through new generation of social media software. Furthermore, due to the progress of wireless Internet and mobile devices, mobile learning environment has gradually become stable and mature. With the idea of mobile learning and through the services of social media software such as blog, wiki, facebook, del.icio.us, flickr, etc., mobile social networks can be established. Such mobile social networks can facilitate effective communication and collaboration for people with shared interests and accordingly form communities of practice. Through mobile social networks and communities of practice, collective intelligence can be thus realized.

\section{Towards Organizational Performance: Technologies for Knowledge and Competency Management}

It has been often debated that modern businesses depend more on the intellectual assets, such as implicit and explicit knowledge, of the workforce than on the tangible business resources. (Stewart, 1997, Sveiby, 1997) Explicit knowledge can be readily transmitted across individuals formally and systematically. Tacit knowledge is highly personal and hard to formalize. It is deeply rooted in each individual's actions and experiences, as well as the ideals, values and emotions of the human beings.

The modern dynamic life implies the continuous update and improvement of knowledge, skills and competencies. Competitive performance in today's organization requires a sufficient consideration of the acquisition, recognition and use of competencies within the organization. The organization's success likely depends on the one hand, on the perceived value of the products and services offered, and on the other hand, on the competency of the workforce. Thus, organizations aiming at the improvement of their performance must manage the human and structural capital simultaneously, as there is a constant interchange between these two types of 'knowledge.' Moreover, the organizations must manage also knowledge and competencies simultaneously, as there is a constant interchange between the individual and the organization. Against this 
background, knowledge management and competency management define key strategy factors in terms of the organizational performance management.

Knowledge management can be defined as the systematic, explicit and purposeful creation, renewal and application of knowledge to maximize the knowledge-related effectiveness and returns of an organization from its knowledge assets. The goal of the implementation of knowledge management in an organization is to increase the amount of tacit knowledge that an individual has available to solve business problems. Competency management addresses the measurement of and the judgment on the competencies of all employees, in order to determine proper career development plans according to the organization's business objectives.

In a knowledge society, new technology developments facilitate the performance management process by implementing a progressive support and enhancement. Knowledge management systems are used to rapidly collect, process, store, retrieve, maintain, organize and deliver large amounts of enterprise-specific knowledge assets. They are in general terms either for codification of information or personalization. A codification approach ensures an efficient access to information while a personalization approach supports knowledge sharing and facilitates the access to the content and others. Competency management systems involve the analysis of learning gaps, detect redundancy, and provide an awareness of available competencies for the preparation of new assignments, tasks and projects. Toward these aims, these systems have to record and keep track of competencies. Due to the common elements involved in both knowledge management and competency management structures such as the creation of useful knowledge from information or data found in available resources, master knowledge, personalization, interpersonal interaction, cooperation, collaboration, and assessment, knowledge management and competency management are coming closer together but do not yet enjoy full integration.

Seen in this light, the need for interoperability of content, competency and assessment data and systems arises. Portability and reusability become a key source for standardization activities, on the one hand. On the other hand, a methodical and strategic approach towards prospective technological organizational and individual performance developments appears to be a major factor for innovation and competitive improvement in organizations to maximize their Return-On-Investment in people and technology. Individualization, personalization, adaptation and social inclusion turn into a core characteristic of the society's quality.

\section{Open Technologies, Standards and Content}

The "open" trends are forming a new stream in education (Iiyoshi \& Kumar, 2008). These trends include open technology, open content and open knowledge. As the open educational technology, there are numerous activities to develop open source educational platforms such as learning management systems, e-portfolio systems and content registry. As another open educational technology trend, open standard activities play important role to disseminate learning technologies. The open standards deal with learning content format and metadata, learner information, skill and competency information as well as learning design information. In addition, various educational organizations are providing their educational resources as open content which gives opportunity for the people outside the organization to freely access these resources. 
These open trends can be found not only in education but in the broader field especially in the information and communication technology (ICT) industry (Nakabayashi, 2009). With the open trends, the people can enjoy freely available resources. However, the meaning of the open trends is more than that. One of the significant impacts of open trends is the embedded mechanism to increase the "value" by competition and cooperation. This mechanism is enabled by the "power of modularity" (Baldwin \& Clark, 2000). Modular system equipped with open interface based on open standards allows an open community of people to add or replace modules with new functionality or high performance without damaging the functionally of the whole system. This results the overwhelmingly rapid improvement of the original system that is impossible with a closed system. Another important aspect of open trends is the facilitation of collective knowledge creation (Raymond, 1997). As seen in the development process of open source software such as Linux, the continuous cycle of design, implementation, evaluation and feedback is formed in the open source community. This cycle is enabled by the shared open information, parallel and distributed problem solving, and participants with high motivation to contribute to the open project where they can be recognized as a "cool" engineer. This development cycle in the open community is the key to create high quality products from an open source software project.

It has been realized that the above mentioned mechanism behind the open trends in the ICT industry can be generalized also to education. Thus the open education, combined with e-learning and other ICT application, is attracting a lot of attention. The idea of this trend is to provide an education and learning opportunity with a high quality and flexibility, supported by the open community mechanism in which the knowledge is constantly created, evaluated and sophisticated. Open technology, open standards and open content are the elements to foster this mechanism.

\section{Preview of Papers}

Eight papers were accepted in this special issue. The first paper deals with automatic quiz generation which is one of the important topics for learner assessment in the advanced learning technology area. In this paper, Goto, Kojiri, Watanabe, Iwata and Yamada (2010) propose a system to automatically generate multiple choice questions for English sentence tests. They developed a question generation system to extract knowledge from existing question based on machine learning technologies.

In the second paper, Fujishiro and Miyaji (2010) discuss the effect of blended instruction for English oral communication. They combine web-based training courseware with group discussion and peer tutoring, and evaluate the learner's achievements in relation to the learner's personality.

The third paper proposes a novel mechanism for leaner adaptive self-learning environment. Nakabayashi, Morimoto and Hada (2010) designed a learning environment based on the idea of a "courseware object" which allows a function extensibility and system-content interoperability at the same time. They apply their idea to implement a standard-based learning system with a function extension flexibility.

In the fourth paper, Devedžić, Radenković, Jovanović, and Pocajt (2010) discuss their project introducing technology-enhanced learning to small/medium companies. They especially focus on collaboration aiming at encouraging knowledge sharing 
between different organizations. They describe the development and test trial to support the implementation of such a collaborative learning environment.

In the fifth paper, Klett (2010) reflects on the need for harmonization of organizational and individual performance, e-learning, competency management and assessment in the framework of rising multinational and international businesses and introduces the requirement for an aligned quality management. It shows a holistic technological approach that focuses on the complex interrelationship between strategic management, and performance management and the implied need for interoperability and standardization efforts in these application domains.

The sixth paper introduces the knowledge management practice in a research community. In this paper, Shih, Nuutinen, Hwang and Chen (2010) report their experience of a virtual collaborative community built using a knowledge management system. Based on a knowledge management model, they discuss how the system supports each aspect of the model through their seven years of experience.

In the seventh paper, Huang, Yang, and Hwang (2010) propose a framework of situational language teaching to empower the concept of u-learning and employ SLT pedagogy in a u-learning environment. Their experimental results showed that students with the situational mashups support had better learning performance and behaviours.

In the last paper, Chen (2010) discusses how the virtual stores are accepted by retailers. A theoretical model was constructed to describe the retailers' intention, then the model was tested using collected data showing that a high quality training system is important to increase the retailers intention to use virtual stores.

\section{References}

1 Baldwin C. Y. \& Clark K. B. (2000). Design Rules, Vol. 1: The Power of Modularity. Boston, MA: The MIT Press.

2 Chen, I.Y.L. (2010). Understanding Retailers' Acceptance of Virtual Stores. Knowledge Management \& E-Learning: An International Journal, 2(3), 328-336.

3 Devedžić, V., Radenković, S., Jovanović, J. \& Pocajt, V. (2010). Specifying Cases for Technology Enhanced Learning in a Small and Medium Enterprise. Knowledge Management \& E-Learning: An International Journal, 2(3), 260-277.

4 Fujishiro, N. \& Miyaji, I. (2010). The Effects of Blended Instruction on Oral Reading Performance and their Relationships to a Five-Factor Model of Personality. Knowledge Management \& E-Learning: An International Journal, 2(3), 225-245.

5 Goto, T., Kojiri, T., Watanabe, T., Iwata, T. \& Yamada, T. (2010). Automatic Generation System of Multiple-Choice Cloze Questions and its Evaluation. Knowledge Management \& E-Learning: An International Journal, 2(3), 210-224.

6 Huang, A.F.M., Yang, S.J.H. \& Hwang, G.J. (2010). Situational Language Teaching in Ubiquitous Learning Environments. Knowledge Management \& E-Learning: An International Journal, 2(3), 312-327.

7 Iiyoshi, T. \& Kumar, V. (Ed.) (2008). Opening Up Education: The Collective Advancement of Education through Open Technology, Open Content, and Open Knowledge. Boston, MA: The MIT Press. 
8 Klett, F. (2010). The Design of a Sustainable Competency-Based Human Resources Management: A Holistic Approach. Knowledge Management \& E-Learning: An International Journal, 2(3), 278-292.

9 Nakabayashi, K. (2009). Impact of Standardisation and Open Source Software in e-Learning. Raquel Hijon (Eds.) Advanced Learning (pp. 315-328). Vienna: IN-TECH.

10 Nakabayashi, K., Morimoto, Y. \& Hada, Y. (2010). Design and Implementation of Extensible Learner-adaptive Environment. Knowledge Management \& E-Learning: An International Journal, 2(3), 246-259.

11 Raymond, E. S. (1997). The Cathedral and the Bazaar. http://www.catb.org/ esr/writings/cathedral-bazaar/cathedral-bazaar/.

12 Shih, J.L., Nuutinen, J., Hwang, G.J. \& Chen, N.S. (2010). Building Virtual Collaborative Research Community Using Knowledge Management Approach. Knowledge Management \& E-Learning: An International Journal, 2(3), 293-311.

13 Stewart, T. A. (1997). Intellectual capital: the new wealth of organizations. New York: Doubleday.

14 Sveiby, K. E. (1997). The New Organizational Wealth. San Francisco: BerrettKoehler. 